$\xi_{p}$

\title{
Modeling Analysis of Guided Ultrasonic Waves in Composite Plates with Impact Damage
}

\author{
Noorfaten Asyikin Ibrahim ${ }^{1}$, Bibi Intan Suraya Murat ${ }^{2 *}$ \\ ${ }^{1}$ Faculty of Mechanical, Universiti Teknologi MARA (UiTM), 40450 Shah Alam, Selangor, Malaysia \\ *Corresponding author E-mail: bb.intan.suraya@gmail.com
}

\begin{abstract}
This paper investigates the propagation of guided ultrasonic waves and the interaction with impact damage in composite plates using a full three-dimensional Finite Element analysis. Impact damage in the composite plate was modeled as rectangular- and T-shaped delaminations. In order to provide guidelines for extending the modeling of realistic multimode impact damage, the impact damage was modeled as a combination of the delamination and reduced materials properties. The information obtained from these methods was compared to the experimental results around the damage area for a validation. There was a reasonable similarity between the experimental and FE results. The FE simulations can effectively model the scattering characteristics of the $\mathrm{A}_{0}$ mode wave propagation in anisotropic composite plates. This suggests that the simplified and easy-to-implement FE model could be used to represent the complex impact damage in composite plates. This could be useful for the improvement of the FE modeling and performance of guided wave methods for the in-situ NDE of large composite structures.
\end{abstract}

Keywords: amplitude, composite plate, delamination shape, guided ultrasonic waves, reduction properties.

\section{Introduction}

Composite materials offer an improved strength to weight capacity advantages which widely used in aerospace industry. However, the composites always experiencing delamination and cracks when subjected to impact loading [1]. Low impact damage give inner delamination which is barely visible from the outside [2]. Matrix cracking, delaminations, fiber debonding and fiber breakage are the typical hidden damages that can lead to a reduction of structural integrity [3]. In order to ensure the integrity of the composite structure, it is important to detect these hidden damages for a safe operation of the structure.

Currently, there are many types of non-destructive evaluation (NDE) methods, but most of them are selective to certain application and defects. In this study, the focus is to investigate the capability of Guided Ultrasonic Waves (GUW) to be used for monitoring a large composite structures. This because it can propagate over a long distance with less energy loss which promising less time-consumption and also cost-effective [4][5]. The propagation of the first-asymmetrical wave mode $\left(\mathrm{A}_{0}\right)$ mode is studied, because it has shown good damage detection in composite plates [6]. Its less scattering behavior allowed for a better deal in composite study [7]. However, there were some complexity in understanding the propagation and scattering of the $\mathrm{A}_{0}$ mode, especially in composite structures [8] because of the anisotropic properties of the composite materials.

Scattering of guided waves by defects in a composite structure is a complex problem for a NDE. Scattering characteristics such as arrival time, amplitude, frequency content, attenuation, reflected and transmitted waves are normally used to explain the wave propagation in the defective area, but depends on many factors such as the excitation frequency, geometry of the structure, mate- rial properties, direction of propagation, and interlaminar conditions.

In order to study the practicality of the GUW on composites, the capability of the method is studied using Finite Element Modelling (FEM). By simulating the GUW propagation through animations and graphical presentation, these help for a better understanding of the GUW behavior [9]. A 2D FE model is normally used because it is easy to model the composite structure and modify some structural parameters [10][11]. However, a 3D FE model is better in handling a complex geometry and large number of finite element discretization [12]. Recently, numbers of investigation composite plate with different shapes of delamination have been studied in both simulation and experimental [13][14][15]. It is found that 3D simulations can accurately predict the wave scattering at delamination area. Commonly, the study of composite plate with damage assumed a single layer of delamination [11]. Recent study shows that the impact damage affected more than one layer inside of the composite plate [16]. This explained that the material integrity at each layers of composite plate nearby the damage area has been disturbed.

From the literature, the potential for the impact damage in composites has been demonstrated, but the interaction of the guided waves with the complex and multi-mode impact damage requires improved understanding. It is quite challenging for producing an accurate modelling of a real impact employing full 3D analysis [17]. Varieties of factors affect the propagation and scattering of guided waves in composite structures and could lead to inaccurate monitoring and defect detection results. This motivates the authors to study the interaction of guided waves with real impact damage in composite plate. This study could then provide an insight for the NDE of composites. 


\section{Finite Element Modeling}

The composite plate model is created in three-dimensional (3D) shape using ABAQUS/Explicit software. Plate size $500 \mathrm{~mm} \times 500$ $\mathrm{mm} \times 2 \mathrm{~mm}$ is coded in Matlab, for easy parameter alternations. The plate consists of 8 layers of [0/90] $]_{2 \mathrm{~s}}$ lay-up with $0.25 \mathrm{~mm}$ thick each. The material properties of the plate is obtained from [18] using the properties of unidirectional composite plate. Element size of $1 \mathrm{~mm} \times 1 \mathrm{~mm}$ with chosen type as an 8-node linear brick with reduced integration (C3D8R) resulting in 2 million elements to model the plate. Excitation point is located $100 \mathrm{~mm}$ from the center of the delamination, exciting the $\mathrm{A}_{0}$ wave in thickness direction. The excitation signal consists of 5 cycle sinusoidal tone burst modulated by Hanning window with $100 \mathrm{kHz}$ frequency. The GUW signals were captured by a $200 \mathrm{~mm}$ length of line scan across the delamination and a $30 \mathrm{~mm}$ radius of circular scan from the center of delamination. In this study, two delamination shapes were modeled: T-shaped and rectangular-shaped delamination.

\subsection{T-Shaped Delamination}

T-shaped delamination was modeled based on the ultrasonic Cscan result from an experimental work previously [19]. As can be seen in Figure 1, the T-shaped delamination was approximated from the C-scan result, highlighted by the red dotted line. Using this approximation, the composite plate with T-shape delamination was modeled in MATLAB, as shown in Figure 2. The delamination was positioned at $1 \mathrm{~mm}$ depth.

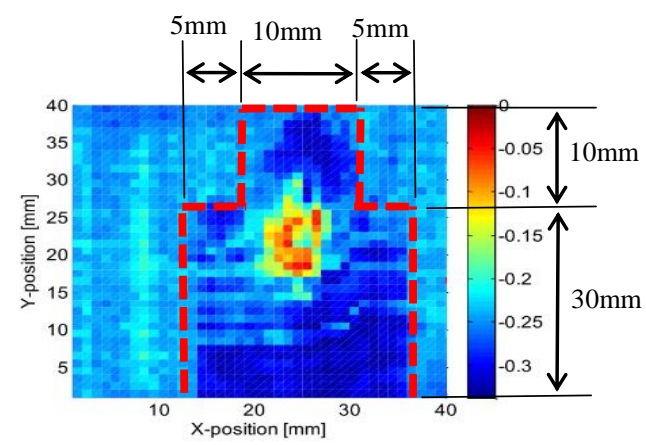

Fig1: Ultrasonic C-scan results of real impact damage on composite plate Dotted red line represents the approximation of the T-shaped delamination.

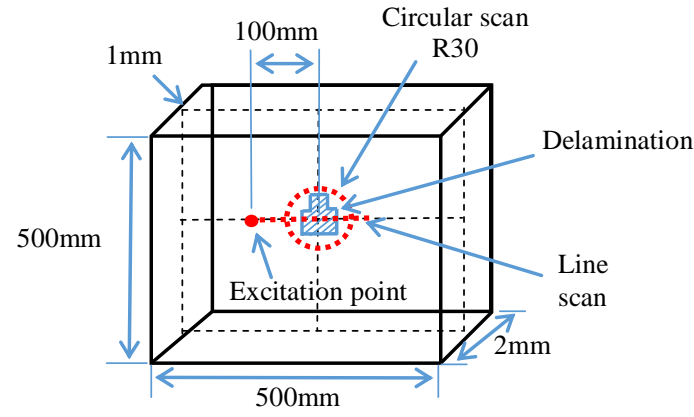

Fig 2: Composite plate size $500 \mathrm{~mm}$ x $500 \mathrm{~mm}$ x $2 \mathrm{~mm}$ with T-shaped delamination in the center; excitation point $100 \mathrm{~mm}$ from the center; circular scan at $30 \mathrm{~mm}$ radius; line scan $200 \mathrm{~mm}$ length; delamination located at $1 \mathrm{~mm}$ depth.

\subsection{Rectangular-Shaped Delamination}

A simple rectangular shape of delamination was used as one of the shapes. This model helps to reduce the complexity and time in writing MATLAB program codes for the composite plate with impact damage. From Figure 3, it can be seen that the impact damage can be generalized as a rectangular shape, making the overall size of the impact damage is about $20 \mathrm{~mm} \times 40 \mathrm{~mm}$. The model is presented in Figure 3, where the location was kept similar, at the center of the plate and at $1 \mathrm{~mm}$ depth.

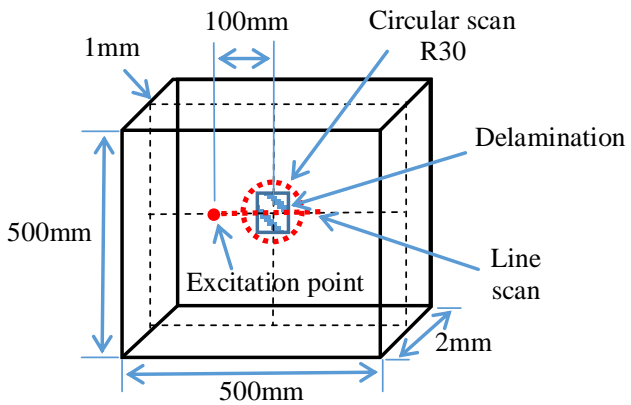

Fig 3: Composite plate size $500 \mathrm{~mm}$ x $500 \mathrm{~mm} \times 2 \mathrm{~mm}$ with $20 \mathrm{~mm} \times 40$ $\mathrm{mm}$ rectangular shape delamination; excitation point at $100 \mathrm{~mm}$ from the center of delamination; circular scan at $30 \mathrm{~mm}$ radius; line scan $200 \mathrm{~mm}$ length; delamination located at $1 \mathrm{~mm}$ depth.

\subsection{Reduced Stiffness Properties}

In order to develop more realistic damage implementation, there is a need for accurate and practical modeling of impact damage in composite structures. In this study, the stiffness properties at the defective region were reduced. This was to represent the impact damage zone that was strongly micro-cracked. The reduction of stiffness properties was set at full thickness of the composite plate with $75 \%$ reduction, located at the same area of the delamination. The $75 \%$ reduction properties was selected based on the study in [19]. Figure 4 shows the illustration of the plate with combined delamination and reduced stiffness properties.

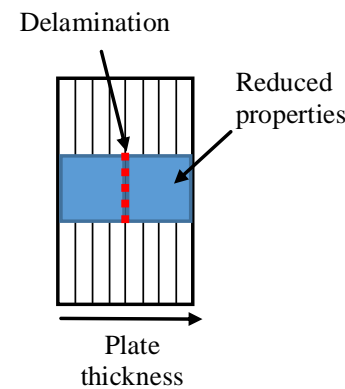

Fig 4: Side view for composite plate with combined delamination and reduced properties.

\section{Guided Ultrasonic Waves Scattering at Im- pact Damage}

\subsection{Influence of Delamination Shape on Wave Scatter- ing}

In practice impact leads to irregularly shaped damage patterns, but many researchers have used either the circular or the rectangular delamination shapes for $\mathrm{FE}$ simulations of guided ultrasonic waves. In this section it is considered whether a simple rectangular delamination shape can be used, which is straight-forward to implement in a FE model. Two regular shapes to represent a delamination are investigated: rectangular and $\mathrm{T}$-shaped delamination. Both scattering results were compared to the experimental results obtained previously in a separate study [19]. As can be seen from Figure 5, both FE models resulted in a comparable amplitudes pattern, especially in the region of before delamination region and in the defective area. However, in the region of past delamination, different patterns of forward propagating waves between the two models can be observed. A possible explanation for this might be related to the different delamination shapes and edges of the two 
models. The T-shape model has more edges than the rectangular shape, which causes more guided waves to be reflected in the delamination region. Hence, this causes the increment in the forward scattering amplitudes due to the major interferences activities inside the delamination region.

Similarly, as can be seen in Figure 6, both delamination shapes shows different pattern of forward propagating waves. At $330^{\circ}$ direction, a match pattern can be observed, which is due to a matching size of the delamination width $(20 \mathrm{~mm})$. As expected, the opposite directions $\left(0^{\circ}-60^{\circ}\right)$ have dissimilar wave patterns due to different edges of delamination shapes.

In contrast, it is obvious that the experimental results show a significant increase in the amplitude over the damaged area. This may indicate an additional factor that has influenced the signals to behave in such way, since impact damage normally consist of multi-mode damages. The following section investigate the scattering field by both shapes of delamination. The aim is to see whether there any variations in the scattered fields when guided waves interact with different shapes of delamination.

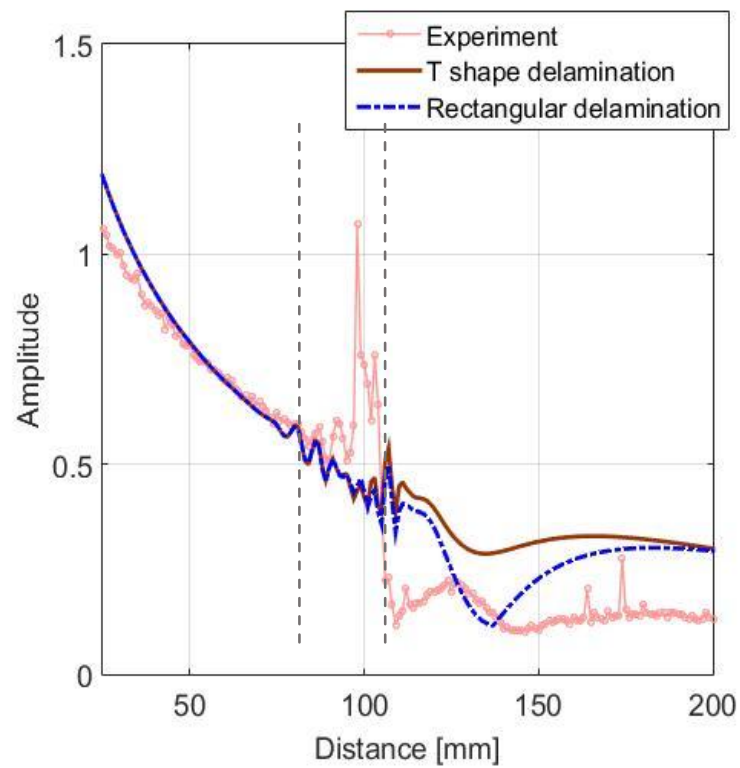

Fig. 5: Maxima of signal envelope across plate with $T$ and rectangular shape delamination compared to the experimental result.

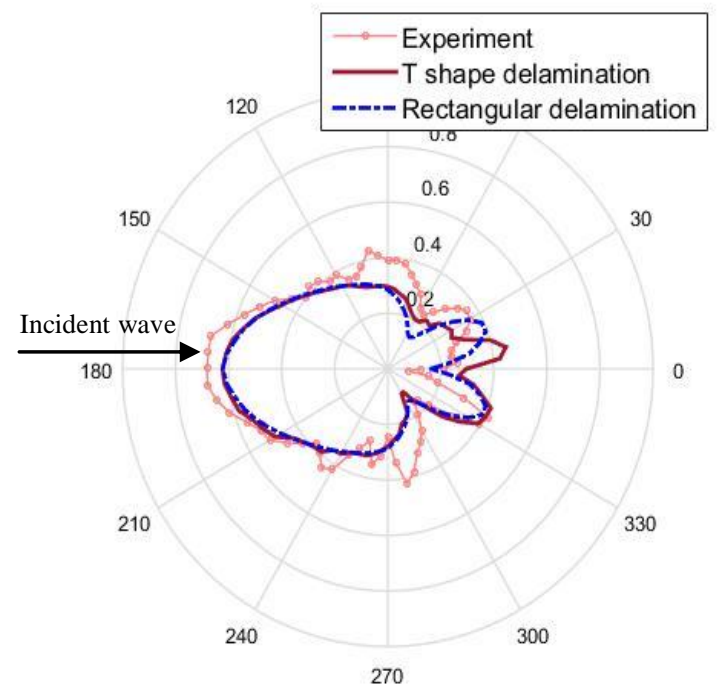

Fig. 6: Wave scattering around delamination for plate with $\mathrm{T}$ and rectangular shape delamination compared with experimental result; measured every $5^{\circ}$ at $30 \mathrm{~mm}$ radius around center of delamination.

\subsection{Visualization of Scattering Field at Delamination}

Two samples of 3D FE simulation was carried out to investigate the scattered field of the $\mathrm{A}_{0}$ mode at two different delamination shapes. Figure 9 presents snapshots of the stress fields at different time instants $(100 \mu \mathrm{s}, 110 \mu \mathrm{s}$ and $120 \mu \mathrm{s})$. Figure $7 \mathrm{a}-7 \mathrm{c}$ represents the scattering field by a rectangular-shaped delamination. Meanwhile, Figure $7 \mathrm{~d}-7 \mathrm{f}$ shows the snapshots of scattering field by a Tshaped delamination. As can be seen from Figure 7, amplitudes of the propagating waves are seen to be higher in the $0^{\circ}$ and $90^{\circ}$ directions as expected for a cross-ply composite plate. Small entry reflection can be observed both Figure $7 \mathrm{a}$ and $7 \mathrm{~d}$. For the rectangular-shaped delamination, two shadow areas began to appear in the forward directions, approximately in the $150^{\circ}$ and $210^{\circ}$ directions. This happened as the wave was being reflected at the upper and lower boundary of the delamination. The same observation can be seen in Figure 7e (T-shaped delamination), but the shadows appear to be more and wider than in Figure $7 \mathrm{~b}$ because of more edges in the T-shaped delamination. Obvious variations in the scattered field patterns can be observed in Figure 7c and 7f, but both shapes of delamination show high intensity waves transmitted across the delamination and advancing to the exit of delamination. A significant portion of the wave reflections inside the delamination area can also be observed from Figure $7 \mathrm{c}$ and $7 \mathrm{f}$. This piece of information helps to improve future optimization strategies for the modeling of guided waves for NDE of composites. Although this study has satisfactorily shown that the FE simulations can effectively model the scattering characteristics of the $\mathrm{A}_{0}$ mode wave propagation in composite plates, a correct model for composite with impact damage should be constructed and selected for future 3D FE models and simulations.

In gaining those insights. Figure 5 and 6 shows a very different wave behaviour between the 3D FE models and the experimental results. The reason for this could be related to the material degradation at the impact damage. It is generally known that the real damage is normally consisting of multi-mode damage such as cracks and delamination. The low-velocity impact towards composite plates may create a strong micro-crack that lead to a local decay in the stiffness properties [20]. To analyze this effect separately, another 3D FE models with combined delamination and material degradation were constructed. The results are presented in the following section.
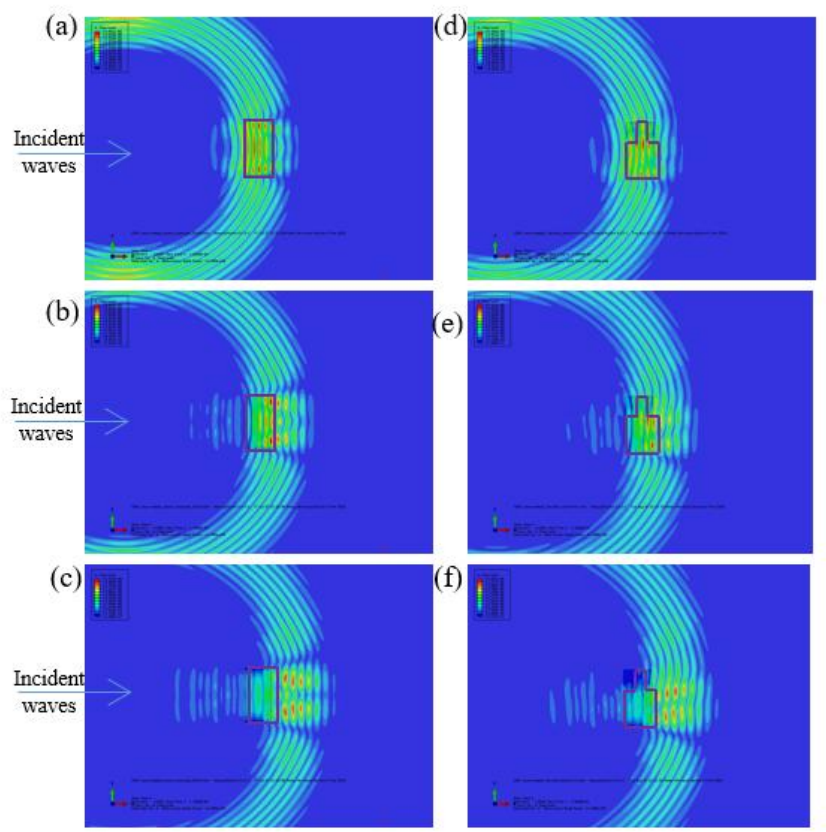

Fig 7: Time snapshots of guided wave propagation and scattering at 100 $\mu \mathrm{s}, 110 \mu \mathrm{s}$ and $120 \mu \mathrm{s}$ respectively; a), b) and c) composite plate with a 
rectangular-shaped delamination; d), e) and f) plate with T-shaped delamination.

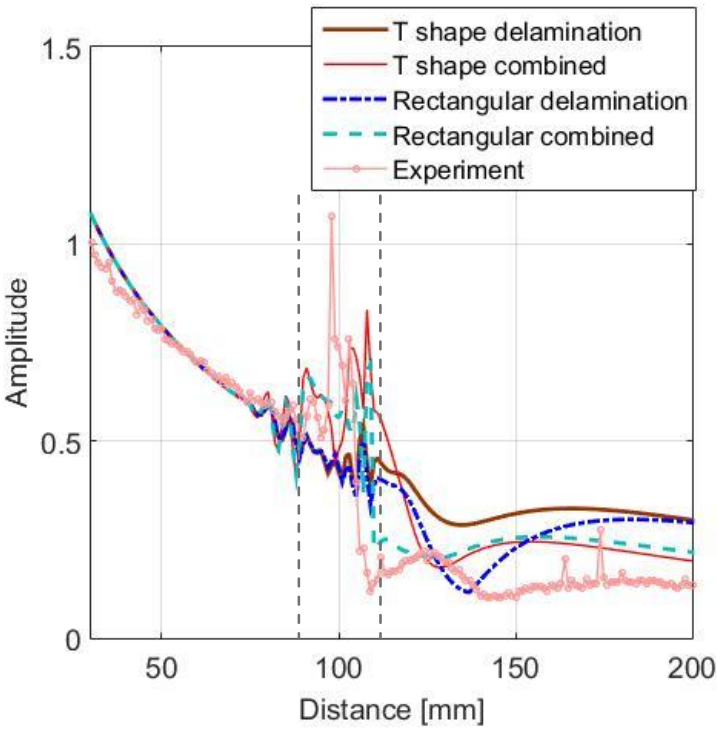

Fig. 8: Maxima of signal envelope across plate with all types of delamination and experimental results.

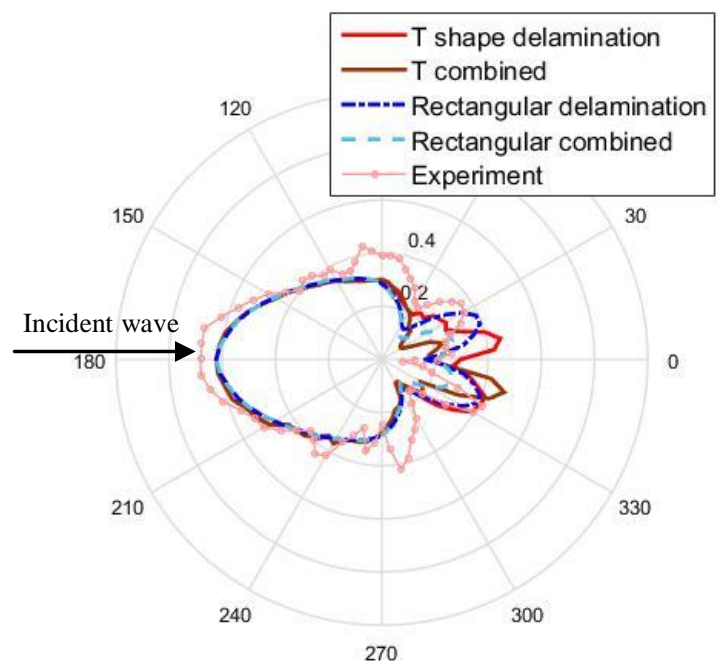

Fig. 9: Scattered amplitudes around delamination for plate with all types of delamination and experimental results; measured every $5^{\circ}$ at $30 \mathrm{~mm}$ radius around center of delamination.

\subsection{Scattering by Multi-Mode Impact Damage}

This section discusses simulation results for the models with combined defects, representing a multi-mode impact damage that consists of a delamination and a through thickness elements with reduced stiffness properties. The results are presented in Figure 8 and 9. From Figure 8, it can be seen that there are large amplitude peaks at the defective region for the models with combined defects. Comparing the models with reduced properties to the model with a delamination only, it can be observed that the amplitudes are significantly higher than the models with delamination only. This could be due to the changes in the wave speed inside the plate, the reduction in stiffness properties produces more waves scattering within the defective region. No clear trend can be found in the region behind the defective area, but models can be seen to have a large amplitude drop upon leaving the defective area. The simulated amplitudes nearly matched the experimental results: (i) higher amplitude peaks in the defective region, increased to $50 \%$ higher than the baseline, (ii) sudden reduction in the amplitude behind the delamination and (iii) then increased back to steady propagation behaviour.

From the angular scattering pattern shown in Figure 9, no clear trend in the forward side lobes can be found. However, the scattered wave magnitudes from the models with reduced material properties seems to be lower than for the model with the delamination only. The largest forward scattered wave can be seen in both T-shape models. Small backward scattering for all models compared to the model with delamination only can be observed. No systematic trend can be observed from the composite model with multiple defects, which demonstrates the complexity of the guided wave scattering. However, the results from this section provide an improved understanding on the influence of the material degradation, although admittedly, the FE models are limited to a particular shaped delamination and elements with reduced material properties.

From these results, it can be concluded that the model with material degradation is needed in order to obtain a more realistic model of the impact damage, which is known to be complex and combine multiple types of defects. A simple and easy to implement rectangular shape can provide an approximated scattering of guided waves, but not accurate.

\section{Conclusions}

The results from this study have shown that the 3D FE model with combined delamination and material degradation is the best model to represent the impact damage in composite plates. The simulation results are comparable to the experimental results: (i) higher amplitude peaks in the defective region, increased to $50 \%$ higher than the baseline, (ii) sudden reduction in the amplitude behind the delamination and (iii) then increased back to steady propagation behaviour. The findings from this study have enabled advances in the modelling of complex defects. The 3D modelling of the combined delamination with the material degradation has opened the perspective of studying any kind of defect using similar approaches, not only limited to a simple shape of delamination model only. This could improve the 3D modelling of the complex impact damage in composites.

\section{Acknowledgement}

The authors gratefully acknowledges the support in funding by Faculty of Mechanical Engineering, Universiti Teknologi Mara (UiTM) Malaysia, and funding from the Geran Dana Pembudayaan Penyelidikan (600-RMI/RAGS 5/3 (12/2015), Kementerian Pengajian Tinggi Malaysia.

\section{References}

[1] K. R. Jagtap, S. Y. Ghorpade, A. Lal, and B. N. Singh, "Finite element simulation of low velocity impact damage in composite laminates," Mater. Today Proc., vol. 4, no. 2, pp. 2464-2469, 2017.

[2] T. J. Swait, F. R. Jones, and S. A. Hayes, "A practical structural health monitoring system for carbon fibre reinforced composite based on electrical resistance," Compos. Sci. Technol., vol. 72, no. 13, pp. 1515-1523, Aug. 2012.

[3] B. I. S. Murat, P. Khalili, and P. Fromme, "Impact damage detection in composite panels using guided ultrasonic waves," Heal. Monit. Struct. Biol. Syst., vol. 9064, pp. 286-293, 2014.

[4] D. N. Alleyne, B. Pavlakovic, M. J. S. Lowe, and P. Cawley, "Rapid, long range inspection of chemical plant pipework using guided waves," Key Eng. Mater., vol. 270-273, pp. 434-441, 2004.

[5] J. L. Rose, "Ultrasonic guided waves in structural health monitoring," Key Eng. Mater., vol. 270-273, pp. 14-21, 2004.

[6] L. Mallet, B. C. Lee, W. J. Staszewski, and F. Scarpa, "Structural health monitoring using scanning laser vibrometry: II. lamb waves for damage detection," Smart Mater. Struct., vol. 13, no. 2, pp. 261-269, 2004.

[7] M. H. Sherafat, R. Guitel, N. Quaegebeur, L. Lessard, P. Hubert, 
and P. Masson, "Guided wave scattering behavior in composite bonded assemblies," Compos. Struct., vol. 136, pp. 696-705, 2016.

[8] M. J. S. Lowe, G. Neau, and M. Deschamps, "Properties of guided waves in composite plates, and implications for NDE," AIP Conf. Proc., vol. 700, no. 1, pp. 214-221, 2004.

[9] J. L. Rose, "Successes and challenges in ultrasonic guided waves for NDT and SHM," in Proceedings of the National Seminar \& Exhibition on Non-Destructive Evaluation, 2009.

[10] S. Santapuri, J. J. Scheidler, and M. J. Dapino, "Two-dimensional dynamic model for composite laminates with embedded magnetostrictive materials," Compos. Struct., vol. 132, pp. 737-745, 2015 .

[11] B. Masserey, C. Raemy, and P. Fromme, "High-frequency guided ultrasonic waves for hidden defect detection in multi-layered aircraft structures," Ultrasonics, vol. 54, no. 7, pp. 1720-1728, 2014.

[12] C. T. Ng, M. Veidt, L. R. F. Rose, and C. H. Wang, “Analytical and finite element prediction of Lamb wave scattering at delaminations in quasi-isotropic composite laminates," J. Sound Vib., vol. 331, no. 22, pp. 4870-4883, 2012.

[13] B. Intan, S. Murat, and P. Fromme, "3D finite element modelling of guided wave scattering at delaminations in composites," AIP Conf. Proc., vol. 1706, no. 101, 2016.

[14] W. Sun, Z. Guan, T. Ouyang, R. Tan, and X. Zhong, "Effect of stiffener damage caused by low velocity impact on compressive buckling and failure modes of T-stiffened composite panels," Compos. Struct., vol. 184, pp. 198-210, 2018

[15] B. I. S. Murat, P. Khalili, and P. Fromme, "Scattering of guided waves at delaminations in composite plates," J. Acoust. Soc. Am., vol. 139 , no. 6 , pp. 3044-3052, 2016.

[16] C. A. C. Leckey, M. D. Rogge, and F. Raymond Parker, "Guided waves in anisotropic and quasi-isotropic aerospace composites: three-dimensional simulation and experiment," Ultrasonics, vol. 54 no. 1, pp. 385-394, 2014.

[17] O. Mesnil, C. A. C. Leckey, and M. Ruzzene, "Instantaneous wavenumber estimation for damage quantification in layered plate structures," Heal. Monit. Struct. Biol. Syst., pp. 1-9, 2014

[18] G. Neau, "Propagation of Lamb waves in anisotropic and absorbing plates: Theoretical derivation and experiments," AIP Conf. Proc., vol. 615, pp. 1062-1069, 2002.

[19] B. I. S. Murat and P. Fromme, "Propagation and scattering of guided waves in composite plates with defects," Int. J. Automot. Mech. Eng., vol. 13, no. 3, pp. 3728-3741, 2016.

[20] H. Y. Choi, H. T. Wu, and F. Chang, "A new approach toward understanding damage mechanisms and mechanics of laminated composites due to low-velocity impact: Part II--analysis," $J$. Compos. Mater., vol. 25, no. 8, pp. 1012-1038, Aug. 1991. 